\title{
EL ESTILO DE LA HISTORIA EN LOS TIEMPOS DE GUERRA: GILBERTO FREYRE Y LOS ENSAYISTAS LATINOAMERICANOS EN LA OBRA DE FERNAND BRAUDEL
}

\author{
Susanne Klengel \\ Universidad Libre de Berlín \\ klengel@zedat.fu-berlin.de
}

\section{RESUMEN / RESUMO / ABSTRACT}

El artículo se propone reflexionar sobre las experiencias y lecturas latinoamericanas de Fernand Braudel en el contexto de la formación histórica de la Escuela de los Annales y en el de la génesis de su obra fundacional sobre el Mediterráneo, publicada en 1949, en el período de la segunda posguerra. Durante su estancia en Brasil (1935-1937), así como posteriormente en su cautiverio de guerra en Alemania y en los años de la posguerra, Braudel leyó intensamente no solo la obra de Gilberto Freyre sino también de otros ensayistas de América Latina, por ejemplo las de Ezequiel Martínez Estrada y Benjamín Subercaseaux. Su interés por las estructuras de la longue durée favoreció su susceptibilidad por las representaciones panorámicas de la "Casa Grande" colonial brasileña y otros textos de Freyre, pero también por las descripciones expresivas de la geología y de los paisajes latinoamericanos presentes en otros autores del continente. El autor de la historia de longue durée del "mare nostrum", obra que asimismo pone de manifiesto su conciencia de estilo, es presentado como un lector atento a los ensayos latinoamericanos que no solamente apreció por sus búsquedas identitarias sino, expresamente, por el estilo ensayístico-literario de su escritura.

PALABRAS ClAVE: historiografía francesa, Fernand Braudel, Gilberto Freyre, ensayo latinoamericano, Segunda Guerra Mundial, posguerra.

Este artigo se propõe a refletir sobre as experiências e leituras latino-americanas de Fernand Braudel no contexto da formação histórica da Escola dos Annales e da gênese de sua obra fundacional sobre o Mediterrâneo, publicada em 1949, no período do segundo pós-guerra. Durante sua estadia no Brasil (1935-1937), assim como posteriormente em seu cativeiro de guerra na Alemanha nos anos do pós-guerra, Braudel leu intensamente não só a obra de 
Gilberto Freyre, mas também outros ensaístas da América Latina, por exemplo, Ezequiel Martínez Estrada e Benjamín Subercaseaux. Seu interesse pelas estruturas da longue durée favoreceu sua susceptibilidade às representações panorâmicas da "Casa Grande" colonial brasileira e outros textos de Freyre, mas também às descrições expressivas da geologia e das paisagens latino-americanas presentes em outros autores do continente. O autor da história da longue durée do "mare nostrum", obra que também manifesta sua consciência de estilo, é apresentado como um leitor atento dos ensaios latino-americanos que os apreciou não só por suas buscas identitárias, mas, expressamente, pelo estilo ensaístico-literário de sua escrita.

PaLAVRAS-CHAVE: Historiografia francesa, Fernand Braudel, Gilberto Freyre, ensaio latinoamericano, Segunda Guerra Mundial, Pós-guerra.

This article aims to reflect upon the Latin American experiences and interpretations regarding Fernand Braudel's work in the context of the historical formation of the Annales School and the genesis of his foundational work on the Mediterranean, published in 1949, in the post-World War II period. During his stay in Brazil (1935-1937), and later during in his war captivity in Germany in the post-war years, Braudel was a thorough reader not only of Gilberto Freyre's work, but also other Latin Amrican authors, for instance Ezequiel Martinez Estrada and Benjamin Subercaseaux. His interest in the longue durée structures made him prone to the scenic representations of the Brazilian colonial "Casa Grande" and other texts by Freyre, but also the expressive descriptions of Latin American geology and landscapes by other authors of the continent. The author of the longue durée history and the "mare nostrum", a work that also shows his stylistic sensitivity, he is displayed as a careful reader of Latin American writings, appreciated by him not only for their search for an identity, but, specifically, the essayistic and literary style.

KEYWORDS: French Historiography, Fernand Braudel, Gilberto Freyre, Latinamerican Essay, World War II, Postwar.

En un debate con ocasión de un coloquio franco-brasileño en 1990, el historiador francés Frédéric Mauro colocó una pregunta algo provocadora sobre el contexto histórico en la formación de la célebre Escuela de historiografía de los Annales:

Une Histoire à la fois géographique et économique, anthropologique et culturelle, attachée aux structures qui bougent avec lenteur, bref, une Histoire à la Brésilienne, n'était-ce pas précisément le programme des Annales? (Mauro 735-736).

El historiador hacía con ello alusión a la obra del sociólogo y antropólogo brasileño Gilberto Freyre, sobre todo a su obra Casa Grande \& Senzala (1933) que en el área de las ciencias sociales y humanidades francesas de la segunda posguerra había llamado bastante la atención. Fue publicada en 
francés con el título Maîtres et Esclaves en el año 1952 traducida por Roger Bastide y acompañada de un prefacio de Lucien Febvre; Roland Barthes, por su parte, escribió una reseña entusiasta en la que refirió:

C'est un livre exceptionnel à beaucoup points de vue [...] c'est la quadrature du cercle des historiens; réalisée ici, le point ultime de la recherche historique, de l'aveu même d'hommes comme Michelet ou Marc Bloch (Barthes 108).

En aquellos años de la posguerra, Gilberto Freyre llegó a ser una personalidad de renombre internacional cuya competencia científica en "cuestiones raciales" era muy solicitada por ejemplo entre los expertos de la UNESCO; por otro lado, en su calidad de experto de la convivencia de culturas, Freyre fue a su vez invitado por el presidente del Estado Novo portugués, Salazar, a emprender un viaje de estudio y conferencias a las colonias portuguesas de África y Asia (1951/52), viaje que le serviría para elaborar su controvertida teoría sobre una nueva cultura transnacional lusotropicalista.

En el presente artículo, mis reflexiones se refieren, no obstante, a las lecturas y al descubrimiento temprano de la obra de Freyre (y de otros pensadores y escritores latinoamericanos) por parte del historiador francés Fernand Braudel durante y después de su estancia como docente (1935-1937) en la recién fundada Universidad de São Paulo y luego en los años 40. El estudio quiere demostrar que este descubrimiento se caracteriza particularmente por la atención y admiración que Braudel dedica no solamente a las temáticas de las obras freyrerianas (y de otros escritores) sino también al estilo de escritura, una escritura que se mueve entre ficción, ensayo, sociología, historiografía y (auto)biografía. Este interés que tiene Braudel por la forma no ha pasado desapercibido por la crítica académica; sin embargo, llama la atención que las enunciaciones braudelianas acerca de la escritura ensayística son interpretadas, a veces, como un veredicto sobre algo que sería insuficiente, ambivalente y problemático (ver, p.e., Leenhardt 31-33). El presente artículo propone una relectura que revise las enunciaciones tempranas de Braudel sobre el estilo de los textos latinoamericanos, tanto en el caso de Freyre como en el de otros ensayistas, colocándola en el contexto de los años de la Segunda Guerra Mundial y de la posguerra. Es importante ver estos procesos de recepción y de diálogo acerca de los discursos ensayísticos latinoamericanos en el ámbito de un mundo europeo que se encuentra en profunda crisis para comprender la atracción de los textos tanto como las posibles reservas frente a ellos. 


\section{DE CORRIENTES MARINAS Y LUCIÉRNAGAS}

Dos imágenes forjadas por Fernand Braudel han llamado mucha atención a lo largo del tiempo: se trata de imágenes que buscan captar e ilustrar las diferencias entre el mundo rápido de los acontecimientos y el mundo lento, estructural de la longue durée. En su célebre estudio sobre La Méditerranée et le Monde méditerranéen à l'époque de Philippe II (1949), Braudel compara la historia de los acontecimientos, es decir, la historia tradicional, con el juego nervioso de las ondas en la superficie del mar que llama la atención como historia palpitante, de pasiones humanas individuales, políticas, y experiencias vividas. Pero los acontecimientos son efímeros y pierden importancia frente a otras temporalidades históricas, frente a aquella historia social más lenta de los grandes ritmos de las poblaciones y del comercio que se asemejan a las corrientes del mar profundo; y aquella anclada en la geografía, casi inmóvil, igual a las aguas silenciosas del fondo del mar (véase Braudel, La Méditerranée 1949, XIII).

En la segunda imagen, también famosa, Braudel compara los acontecimientos históricos con el breve destello y la subsiguiente extinción de pequeñas luces en la noche: "Les événéments traversent l'histoire comme des éclairs successifs. A peine naissent leurs lueurs que déjà la nuit les engloutit" (Braudel ibíd., $721)^{1}$. La imagen parece referirse al fenómeno del relampagueo, sin embargo, está fundada en los recuerdos que Braudel tiene de una estancia en Bahía. Poco tiempo después de la publicación de su libro sobre el Mediterráneo (1949), en su discurso inaugural en el Collège de France, Braudel atribuyó la imagen de las luces repentinas a los enjambres de luciérnagas:

J'ai gardé le souvenir, une nuit, près de Bahia, d'avoir été enveloppé par un feu d'artifice de lucioles phosphorescentes; leurs lumières pâles éclataient, s'éteignaient, brillaient à nouveau, sans trouer la nuit de vraies clartés. Ainsi les événements: au delà de leur lueur, l'obscurité reste victorieuse (Braudel, Écrits 22) ${ }^{2}$.

1 En la segunda edición revisada de 1966, la imagen será más aguzada aún: "Les événements sont poussière: ils traversent l'histoire comme des lueurs brèves; à peine naissent-ils qu'ils retournent déjà à la nuit et souvent à l'oubli" (Braudel, La Méditerranée 1966/2, 223).

2 El origen de la comparación sugerente se lee en los escritos redactados entre 1940 y 1945 en el campo de oficiales de Mainz y Lübeck: 'Il m'est arrivé, un soir, à l'interieur de l'État de Bahia, d'être pris brusquement au milieu d'une montée prodigieuse de lucioles 
La importancia de la estancia de Braudel en Brasil ha sido destacada por Giuliana Gemelli (55-73), Peter Burke, Maria Lúcia G. Pallares-Burke (2008) y otros. El propio Braudel, en su "Personal Testimony" llamó al Brasil un "paradise for work and reflection [...] I spent three marvellous years [...] In winter, during the period of my southern vacations, I was in the Mediterranean; the rest of the year, in Brazil, with leisure and fantastic possibilities for reading" (Braudel, Personal Testimony 452). El hecho de que Braudel, en aquel entonces, había sido un asiduo lector de la producción intelectual brasileña, y también de obras literarias-ensayísticas es aún poco reconocido. Más tarde extendería su interés a otras literaturas latinoamericanas. Esta disponibilidad, así como su actitud abierta para con la producción de autores y escritores latinoamericanos demuestran la importancia del Brasil y de América Latina que a su vez tuvieron una influencia constatable en la propia producción historiográfica.

\section{LECTURAS DEL CAUTIVERIO}

Durante la Segunda Guerra Mundial se publicó un artículo extenso de Fernand Braudel, títulado "A travers un continent d'histoire. Le Brésil et l'œuvre de Gilberto Freyre” (1943), en la revista historiográfica francesa Annales, que durante los años de la ocupación alemana llevó como subtítulo Mélanges d'histoire sociale. El texto fue redactado durante el cautiverio de guerra en Alemania, donde Braudel estuvo detenido entre 1940 y 1945 en diferentes campos de oficiales ${ }^{3}$. En él se presenta el primer estudio exhaustivo y profundo del historiador sobre la obra de Gilberto Freyre ${ }^{4}$. Parece que el artículo había sido un proyecto de largo plazo cuya concretización se había retrasado, debido a la situación política y al cautiverio de guerra. Impulsado

phosphorescentes. Elles éclataient partout sans arrêt, plus ou moins hautes, innombrables, en gerbes au sortir des taillis et des fossés de la route, comme autant de fusées, trop brèves, pourtant, pour éclairer le paysage avec netteté. Ainsi des événements, ces points de lumière". (Braudel, L'histoire 1997, 23-24, ver tambien Gemelli 84).

Ver el artículo detallado de Schöttler (2013) sobre el contexto y las circunstancias del cautiverio.

Ver también los estudios de Leenhardt (2006) y Gerstenberger (2014). 
por Lucien Febvre ${ }^{5}$, el estudio extenso sobre la obra completa de Freyre fue dado a conocer al público francófono diez años después de la publicación de Casa Grande \& Senzala. Formação da família brasileira sob o regime de economia patriarcal (1933), su obra primera y la más famosa hasta el momento. Los detalles del artículo y las exactas descripciones de la obra de Freyre (hasta la referencia de las páginas) indican que los libros reseñados deben haberse encontrado, en gran parte, a disposición de Braudel $^{6}$. Su texto, complejo en cuanto al estilo y al argumento, no es de fácil acceso a la comprensión en su contexto histórico. A primera vista, el artículo se presenta como una reseña detallada, científica que destaca elogiosamente los méritos de Gilberto Freyre, a la vez que también menciona, de forma crítica, ciertas lagunas y ausencias. Pero, mirándolo más de cerca, uno descubre un texto cuyo autor, dividido entre la fascinación por la obra del brasileño y el autocontrol necesario de la propia reacción empática, se ve obligado a operar con múltiples estrategias de escritura para captar y expresar adecuadamente el "fenómeno Gilberto Freyre".

La reacción de Braudel parece menos sorprendente si se piensa en que la escritura de Freyre se ubica muy cerca de una tradición diferente (y más literaria) que aquella desde la cual proviene el historiador francés. En Brasil, Casa Grande \& Senzala fue considerado por la crítica, desde el inicio, no solamente como un texto científico sino también como obra maestra de la literatura ${ }^{7}$. Este juicio doble se debe a su asombrosa mezcla de estilos que va desde el razonamiento científico hasta descripciones coloridas marcadas por otros géneros textuales y el uso de un lenguaje muy directo, personal y

5 En aquellos años del cautiverio, Braudel comienza a redactar su obra La Mediterranée et le Monde méditerranéen à l'époque de Philippe II (Schöttler 2013). Lucien Febvre, sin embargo, no dejó de recordarle a Braudel, según dice la correspondencia, que no se olvidara de trabajar sobre América Latina: "Ne pas lâcher la Méditerrané, ne pas lâcher surtout les études sud-américaines. J'y insiste (...)" (carta del 16 de mayo de 1942, cit. por Gemelli 72).

6 Braudel se refiere, aparte de Casa Grande \& Senzala (1933), a los siguientes textos de Gilberto Freyre: Sobrados e mucambos. Decadência do patriarcado rural no Brasil (1936); Guia prático, histórico e sentimental da cidade do Recife (s.f.); Nordeste. Aspectos da influência da cana e a paisagem do Nordeste do Brasil (1936/1937), así como al opúsculo Mucambos do Nordeste editado por el Ministério de Educação e Saúde (s.f. [1937?].

Véase la compilación de la prensa en Fonseca (1985). Cuando Braudel llegó en São Paulo en 1935, todavía siguieron publicándose reseñas sobre la obra innovadora de Freyre. Debido a sus buenos conocimientos de español, debe haber comprendido las voces de la prensa brasileña. 
empático (por ejemplo en el caso de la descripción de costumbres familiares y eróticas en el universo de la "casa grande" patriarcal en tiempos coloniales) ${ }^{8}$. Braudel comprende y recuerda que el texto podría pertenecer a otro género textual, y continúa caracterizando a Freyre, primero como un "écrivain-né" y después, como sociólogo debido a su procedencia científica (es decir, de la escuela sociológica-antropológica de Franz Boas), pero también como historiador en el sentido de la Escuela de los Annales ("bien plus historien qu'il ne croit, au sens que prend le mot pour un lecteur des Annales", Braudel, A travers 4). Freyre es, según Braudel, un ensayista brillante, agudo, quien sabe documentar de manera impresionante, sus textos según la "tradition vigoureuse des 'essayistes' brésiliens"; Freyre es ensayista, pero "historien en sus; historien privilégié, plein de souvenirs personnels et de souvenirs familiaux" (ibíd. 5). Ve como irresistible la "insistencia proustiana" de los textos, pero la constante perspectiva desde adentro también corre el riesgo, según Braudel, de crear malentendidos entre los lectores extranjeros. Sin embargo, no consigue resistirse al opulento panorama de esta mirada. En este sentido, afirma que después de la lectura casi hechizante se vuelve necesario cerrar los libros para reflexionar, desde afuera y con cierta distancia, sobre los posibles límites de la obra del brasileño (ibíd. 16).

Luego, Braudel enumera algunos de sus reparos en el trascurso del texto. Las dudas se refieren sobre todo a la insistencia de Freyre, demasiado rígida, en un "Brasil sedentario" que no toma en cuenta las grandes migraciones continentales; se refieren también a una cronología de épocas y a los diferentes procesos de desarrollo regional que son poco transparentes, así como al olvido casi total de ciudades coloniales como Recife y Bahía con sus respectivas funciones oficiales y administrativas. Al fin y al cabo deplora la ausencia de otras "realidades colectivas" constitutivas de la sociedad esclavista de la economía del azúcar: como por ejemplo los comerciantes y protagonistas de la vida urbana mercantil vinculados a la venta y la distribución del azúcar (ibíd. 17).

Pero a pesar de ello, el historiador francés no cesa de destacar el carácter sobremanera innovador de los estudios de Freyre, textos libres de repeticiones y estereotipos. La obra de Freyre destacaría particularmente por su mirada

8 En este contexto, ver p. e. la apreciación crítica de Darcy Ribeiro en su prólogo a la edición de la Biblioteca Ayacucho (en Freyre, Casa Grande 1977, IX-XLI). 
hacia los hechos sociales, hacia la dimensión humana como causa profunda de los acontecimientos históricos:

Là où l'on disait: les gouvernants, les capitaineries, le sucre, les races, il [Gilberto Freyre, SK] voit des hommes, des familles, des milieux sociaux, des aristocraties, des peuples d'esclaves (ibíd. 7).

Así, Freyre representa los grandes problemas del pasado brasileño como un historiador social motivado por una mayor "preocupación por lo real": "Personne ne me semble avoir réussi avec plus de bonheur que Gilberto Freyre" (id.).

En la segunda parte de su artículo tripartito se puede observar que el historiador parece atraído no solamente por el contenido sino también por la presentación formal literario-estética. La inclinación de Freyre hacia el estilo literario se nota, por ejemplo, en aquellas imágenes que privilegia (comenzando con la "casa grande", metáfora de la estructura social del Nordeste brasileño en los tiempos de la Colonia) o en las puestas en escena de la vida en la "casa grande" que ya las primeras reseñas brasileñas habían igualado a un "ambiente pantagruélico" . A menudo, Freyre rompe su discurso científico debido a su predilección por el ornato abundante, por acumulaciones verbales casi barrocas, por el recurso a anáforas, paralelismos o también, como contrapunto, por una reducción de la frase a través de la elipsis, como se puede apreciar en la descripción de la crueldad femenina: "O motivo, quasi sempre, o ciume do marido. O rancor sexual. A rivalidade de mulher com mulher" (Freyre, Casa Grande 249). Como ejemplo que pueda demostrar el uso de los registros de estilo heterogéneo citamos el conocido inicio del capítulo IV:

\footnotetext{
"Sabe o leitor o que me fez lembrar o livro sob este prisma, e em ponto pequeno? Rabelais. Sim, "excusez du peu”, Rabelais. Não é senão rabelaisina aquela prodigiosa exposição de frades caprinos, de mulatas e índias que se deitam docilmente, de receitas de doces, de vestuários (até os íntimos), de lutas, de doenças venéreas e outras, de plantas de casas, castelos, engenhos, pomares de atos de sodomia e bestialidade de rebanhos, amores e danças. Todo bem agitado, misturado, conserve-se em lugar fresco e tome-se quando convier. Ambiente pantagruélico, [...] de fábulas e observações científicas, de grandezas e de ingenuidades. No fundo, literatura, muita literatura". Reseña de Afonso Arinos de Melo Franco, publicada el 15 de febrero de 1934 en O Journal (Rio de Janeiro), cit. por Fonseca (81-88, aquí 85). Es interesante que en 1972, un comentarista, criticando la obra La Méditerranée..., destacara precisamente el "espíritu rabelaisino" del texto: "For Braudel has the Rabelaisian spirit in his love not only of stray particulars but of all sorts of general notions" (Hexter 525).
} 
Todo o brasileiro, mesmo o alvo, de cabello louro, traz na alma, quando não na alma e no corpo -há muita gente de jenipapo pelo Brasil-, a sombra, ou pelo menos a pinta do negro. Na ternura, na mimica excessiva, no catholicismo em que se deliciam nossos sentidos, na musica, no andar, na falla, no canto de ninar menino pequeno, em tudo que é expressão sincera de vida, trazemos todos a marca inconfundivel da influência negra. Da escrava ou sinhama que nos embalou. Que nos deu de mamar. Que nos deu de comer, ella propria amollegando na mão o bolão de comida. Da negra velha que nos contou as primeiras historias de bicho e de mal assombrado. Da mulata que nos tirou o primeiro bicho de pé de uma coceira tão bôa. Da que nos iniciou no amor physico e nos transmittiu, ao ranger da cama de vento, a primeira sensação completa de homem. Do muleque que foi o nosso primeiro companheiro de brinquedo (Freyre, Casa Grande 197) ${ }^{10}$.

Braudel, receptivo en cuanto a la "virtud del vocabulario" (Braudel, A travers 20), se deja fascinar por las "pages colorées" (ibíd. 3), los "détails savoureux" (ibíd. 16), por el "calor" y la "claridad" (ibíd. 19) del texto. Freyre, escribe Braudel,

[...] a lancé des mots que nous avons si souvent répétés et il les a à ce point chargés de sens, d'histoire et de poésie, disons d'intelligence, -qu'on ne pourra plus parler du Brésil, voire de l'Amérique, sans qu'ils ne nous montent aux lèvres (ibíd. 20).

Por este motivo, sorprende poco que el propio Braudel, que continúa enfatizando el estilo de Freyre, también comience a utilizar recursos literarios. Pone en escena su propio texto como un viaje que lleva al descubrimiento de un "continent d'histoire". Gilberto Freyre es el guía empático, sobre todo en la ciudad de Recife, y persona versada que le introduce en los secretos de la "casa grande", los cuales forman la base para tejer los hilos de la "narrativa" sobre el devenir de la nación brasileña desde el seno de la familia patriarcal. Se trata

10 La obra se cita aquí siguiendo el texto y la ortografía de la edición de 1936, que es la versión revisada y ampliada por un índice de la primera versión de 1933. En su artículo, Braudel deplora la falta del índice de nombre y materias en la primera edición. Casa Grande \& Senzala es un "work in progress". Será retrabajado y ampliado varias veces, lo que se nota en los prefacios, en el texto y en las ilustraciones. Las primeras dos ediciones contienen, por ejemplo, numerosos diseños del pintor vanguardista Cícero Dias que faltarán en las ediciones posteriores. 
de un viaje hacia la obra del brasileño cuyos textos eran todavía desconocidos en Europa; pero la palabra o metáfora del viaje recuerda quizás también, de forma sutil, el destino del propio Braudel en el cautiverio de guerra del año de 1943: “... lire et relire (surtout si l'on est trop loin), la splendide Guia do Recife..." (ibíd. 10; véase Freyre 1968).

Por lo tanto, se puede decir que incluso las observaciones críticas de Braudel sobre la obra de Freyre confirman al fin y al cabo su profunda aprobación: Braudel, lector apasionado y convencido de que la historia tiene que ser descrita y representada de la manera más global posible, desea leer mucho más de estas exploraciones que tanto le impresionan por sus contenidos y por la forma en que son expresadas. La "narrativa" de Freyre, tan sugerente, no le parece suficientemente panorámica y por eso propone su ampliación: "Je souhaiterais, quant à moi, un élargissement horizontal de son œuvre" (Braudel, A travers 19). Piensa sobre todo en una ampliación de los espacios para incluir, por un lado, las muchas y diversas regiones del Brasil, y por otro, para hacer visible el espacio histórico del Atlántico, aquel "Mediterráneo moderno" que une el continente histórico de Sudamérica con Europa:

Cette vie de l'Océan, suivant qu'elle est faible ou forte, le Brésil (...) se soude à l'immensité marine, ou bascule vers ses profondeurs continentales... Un grand rythme, non pas le seul sans doute, mais dont beaucoup d'autres auront dépendu (ibíd. 19 ss.).

Si tenemos presente que el artículo de Braudel había sido redactado en los años de germinación del proyecto La Méditerranée et le Monde méditerranéen à l'époque de Philippe II, resulta evidente que hay que relacionar aquí la mirada de Freyre hacia las profundidades históricas del Nordeste brasileño, que se sirve de la metáfora de la "casa grande", con la visión panorámica de Braudel sobre el espacio histórico del Mediterráneo. Es lo que sugiere el historiador inglés Peter Burke, conocedor tanto de la historia de los Annales como de la obra de Gilberto Freyre, en su estudio sobre la historia de la Escuela de los Annales cuando afirma que la imagen y el microcosmos de la "casa grande" como metáfora de la sociedad de plantación deben haber impresionado a Fernand Braudel (Burke, French Historical 101) ${ }^{11}$. De modo

11 En un artículo posterior y más detallado sobre ambos pensadores, Burke (1998) prefiere hablar más bien de "afinidades electivas" entre ambos pensadores cuando destaca la cercanía de su interés en la historia. 
semejante, la esposa Paule Braudel describió (sin mencionar a Freyre) la "expérience brésilienne" como uno de los orígenes intelectuales de Braudel:

Le spectacle du Brésil le fascine [...] l'impression de 'voyager en arrière dans l'histoire', comme si l'Europe d'hier pouvait se voir, s'imaginer à travers le Brésil de ce premier $\mathrm{XX}^{\mathrm{e}}$ siècle, avec son agriculture encore itinérante, ses défrichements forestiers, ses grandes familles patriarcales, survivant à la poussée violente de la modernité (Braudel, Paule 241).

En su gran libro sobre el Mediterráneo, el Brasil está más presente que el resto de América, la cual aparece casi solo bajo el aspecto histórico de suministro de la plata y metales preciosos. La posición destacada del Brasil se debe, por un lado, a la relación y los recuerdos personales que atan al historiador francés al Brasil; por otro lado tiene que ver obviamente con las obras de Gilberto Freyre (y las lecturas referidas en el artículo del año 1943) a que hace mención Braudel en varios lugares de La Méditerranée... con el objetivo de ilustrar comparaciones históricas. En los escritos de Freyre, Braudel identifica ejemplos eminentes de la ensayística brasileña, es decir, de un género literario que se destaca por una amplia tradición en toda América Latina. Los textos significan, para el historiador francés, mucho más que las fuentes historiográficas usuales, puesto que debido a su carácter híbrido, le ofrecen posibles inspiraciones metódicas que podrían enriquecer su propio proyecto sobre el tema y objeto histórico complejo que es el Mediterráneo. Esta hipótesis no parece atrevida si vemos la exclamación inequívoca en $\mathrm{La}$ Méditerranée... que es mantenida en la segunda versión revisada de la obra de 1966: "Ici, à titre de comparaison puissante, quelles lumières n'apportent pas les beaux travaux de l'historien sociologue brésilien, Gilberto Freyre?" (Braudel, La Méditerranée 276). De esta cita, llamará la atención que el signo de interrogación original se ha transformado en un signo de exclamación afirmativo en la versión de 1966 (Braudel, La Méditerranée 308).

La mirada de Freyre desde adentro como método sustancial de su historiografía panorámica aumenta la fuerza de la representación. En una conferencia de 1955, refiriéndose a la teoría literaria anglosajona, Freyre denominaba su estrategia como "insight". Con esto, describe el modo de interpretación de hechos históricos basado en la "imaginación" y en una profunda "comprensión", es decir, que el autor propone un acercamiento controladamente empático e imaginativo al material histórico. Los pensadores y obras de referencia son historiadores y escritores como Proust y Daniel Defoe, Michelet, Marc Bloch, 
George Macauly Trevelyan, Thomas Carlyle, Walter Pater y Lytton Strachey, Joaquim Nabuco y Euclides da Cunha (Freyre, Historia 143-45) ${ }^{12}$. Braudel, por su parte, sabía apreciar estas perspectivas y procedimientos aunque no por esto dejó de estar consciente y de advertir a sus lectores de los peligros que tiene una mirada desde la memoria demasiado personal.

Los textos de Freyre fueron accesibles al público francés interesado a comienzos de los años 50. Como ya se ha mencionado, Casa Grande \& Senzala fue publicado en 1952 bajo el título Maîtres et Esclaves (traducido por Roger Bastide y con prefacio de Lucien Febvre). Salió entre los primeros volúmenes de la Colección La Croix du Sud en la Editorial Gallimard que Roger Caillois había fundado para publicar textos literarios contemporáneos de América Latina traducidos al francés. Más tarde, en 1956, también el libro $O$ Nordeste fue publicado en la misma serie titulado Terres $d u$ sucre, y entró en la buena vecindad con escritores como Jorge Luis Borges, Jorge Amado, Rómulo Gallegos, Alejo Carpentier y otros autores latinoamericanos ya clásicos del siglo $\mathrm{XX}^{13}$.

El interés de Braudel por la literatura ensayística de América Latina se hace patente también en otras ocasiones. Aunque las obras del argentino Ezequiel

12 La conferencia de 1955 aclara también que a partir de la segunda posguerra comenzaba a realizarse un intercambio intenso entre los historiadores de los Annales (en particular Lucien Febvre) y Gilberto Freyre. Cabe mencionar aquí un artículo de Freyre publicado en 1946 en el que destaca la importancia de Jules Michelet (coincidiendo en esto con Lucien Febvre). Sus observaciones sobre el estilo de sus obras desembocan en un verdadero homenaje al gran historiador del siglo XIX, así como al escritor Marcel Proust: "Creou [Michelet, S.K.] um estilo novo de procura do tempo perdido e de resurreição do tempo morto: estilo que teria continuador genial naquele outro historiador da gente francesa, êste geralmente considerado romancista e limitado pela doença e talvez pelo temperamento ao estudo da aristocracia e das suas margens sociais. Refiro-me a Marcel Proust". Al reparo general de que no se puedan igualar novelas y obras históricas, Freyre contesta: "Nada mais injusto [...] Há uma zona de atividade intelectual em que o poder de criação e de imaginação de historiadores e romancistas voltados para o passado social com o espírito, ao mesmo tempo científico e lírico -combinação encontrada magnificamente em Proust- é quasi um só ... (Freyre, A propósito, 17).

13 Roland Barthes, en su reseña sobre Maîtres et Esclaves para la revista literaria Les Nouvelles Lettres editada por Maurice Nadeau, describe el libro de Freyre como un producto brillante de la "sensibilité à l'Histoire totale, élaborée en France par des historiens comme Bloch, Febvre ou Braudel". Con su libro, según Barthes, Freyre ha también contribuido a desmistificar el "mito racial" -tema tan impactante en la posguerra- por haber logrado dar una explicación histórica del mestizaje étnico del Brasil: "[...] Freyre est un novateur; il a introduit dans l'histoire de l'homme brésilien une sexologie pensée à l'échelle de l'Histoire" (Barthes 108). 
Martínez Estrada y del chileno Benjamín Subercaseaux no tienen la misma relevancia destacada para Braudel como la obra de Gilberto Freyre, sus temas y formas de expresión también le proporcionaron al historiador francés muchas inspiraciones y conocimientos importantes. Ambos autores son representantes de un movimiento intelectual y literario que (como Gilberto Freyre) se opuso al cientificismo de los estudios históricos, civilizatorios y del progreso del continente marcados por el pensamiento positivista. Desde la publicación de Ariel (1900) de José Enrique Rodó, esta tendencia de pensamiento se había expresado, como es sabido, en una serie de ensayos sobre la esencia de las identidades latinoamericanas. Los textos provienen de diversos campos ideológicos y unieron de modo diferente las representaciones de la realidad propia con las reflexiones de una psicología de los pueblos y con elementos de la teoría cultural de la primera parte del siglo XX. En el nivel lingüístico destacan casi siempre por su estilo personal, narrativo-descriptivo, que muy a menudo tiene un nivel literario seductor, sobre todo cuando se trata de descripciones de paisajes, asuntos locales y costumbres. El ensayo, como dice Liliana Weinberg, tiene que ser ideado como "una poética del pensar, un estilo del decir" (Weinberg 18, el destacado es mío). Los ensayos tienen sus destinatarios ideales; las obras aquí mencionadas promueven el diálogo con los compatriotas de los autores cuando tratan de instigar la reflexión sobre la "esencia" de la nación y sus fundamentos. Braudel ubica también a Gilberto Freyre en esta línea de tradición del pensamiento sobre la nación. El ensayismo brillante del brasileño se debe, según Braudel, al hecho de que Freyre está escribiendo sobre y desde "un pays qui se cherche", es decir, que su obra ofrece antes que todo una reflexión profunda sobre el propio ser. El Brasil, en palabras de Braudel, es

[...] une personne que l'on trouve en soi, autour de soi, devant soi. Une personne qu'il faut comprendre une bonne fois, si l'on veut se comprendre soi-même. Par là s'explique la tradition vigoureuse des 'essayistes' brésiliens (Braudel, A travers 4 ss.).

Tomando en cuenta la relevancia central del tema de la geografía en las obras de Braudel, que como fundamento casi inmóvil de la historia juega un papel destacado para la comprensión del espacio histórico, no es sorprendente que sean precisamente los ensayos dedicados a las constantes geográficas del continente sudamericano y su potencial fundador de la identidad las que hayan llamado la atención de Braudel. 
En el número especial de la revista Annales, con el título "A travers les Amériques Latines", publicado en 1948, Braudel destaca aquellos ensayos de los autores antes mencionados que en sus títulos acentúan ya las alusiones geográficas. Se trata primero de la "magnifique esquisse de mon ami Ezéquiel [!] Martínez Estrada Radiografía de la Pampa", publicada en 1933 (Braudel, Jeu 438) y segundo, del "beau portrait du Chili, lumineux, mais coupé d'ombres noires, de Subercaseaux" (Braudel, Chili 444) con que se refiere al estudio Chile o una loca geografía (1940).

El abarcador ensayo de Martínez Estrada fue redactado, como es sabido, en un período de cambio político y de depresión económica que se hizo notar en Argentina así como en toda América Latina a partir de los años $30^{14}$. El objetivo del autor era diagnosticar sin piedad la esencia del ser argentino a partir de su historia y geografía como una historia de autoengaño y de fracaso en su camino hacia la civilización. De forma idéntica como sucedía con la nueva tecnología, el autor proponía radiografiar el cuerpo y la psique de la nación para demostrar las causas del desarrollo fallido a sus compatriotas. La geografía del Nuevo Mundo habría desencadenado, según el autor, el trauma originario de la soledad. La experiencia terrible de un espacio sin límites en las tierras argentinas habría perdurado desde la Conquista hasta los tiempos presentes - puesto que no hubo nada que conquistar en las profundidades inmensas del territorio. Desde los tiempos de los conquistadores, "señores de la nada" (Martinez Estrada 7), se crearon, según el autor, solo "seudoestructuras" de la civilización y comunicación, por ejemplo, a través de la red ferroviaria que no hizo más que enfatizar la ilusión del poder sobre el espacio y las inmensas distancias. Con un lenguaje casi épico, el autor dirije a sus lectores hacia la soledad profunda de las eras geológicas. Sería aquí donde comienza la equivocación, la gran maniobra del autoengaño: el Nuevo Mundo es, en realidad, un mundo muy viejo, y el viento que sopla por estos espacios parece soplar desde las profundidades de las edades geológicas. Con palabras poéticas y alusiones literarias, Martínez Estrada dramatiza la tragedia de la geografía americana:

Se diría que el viento es el cuerpo sensible de la soledad: denso, como el que Dante puso en el segundo círculo del Infierno para que los amantes no se pudieran unir ni oír, o como el que separó las llamas

14 Radiografía de la Pampa fue reseñada por Marcel Bataillon en el número especial de la revista Annales (1948). 
de los cadáveres de Eteocles y Polínices según una vieja leyenda que Esquilo no conocía ya. Es el viento estéril como el mar, el viento del mar, el mar como viento (Martínez Estrada 91).

Así, este texto extenso, ensayo tan admirado por Braudel por la fuerza sugerente de sus representaciones de la geología y de los paisajes del continente americano, puede haber influido (aunque no se mencione el nombre del autor argentino), en un curso universitario de Braudel ofrecido en 1947/48 sobre el tema de América Latina, cuyos manuscritos son conservados en el Instituto de Ciencias Políticas, en París. En América Latina, afirma Braudel, es el espacio, su inmensidad y su "inhumanidad" ", el que juega el papel constitutivo en la historia de las civilizaciones. La notoria "lucha contra el espacio" pervive desde los días de la Colonia hasta los tiempos presentes: las pocas rutas, una red ferroviaria insuficiente y también la más reciente tecnología de la aviación demuestran ante todo y dramáticamente la "inmensidad" de las distancias latinoamericanas. En todos los tiempos, continúa Braudel, la "inhumanidad de la distancia" ha ejercido influencia en los destinos humanos y en la historia viva de América Latina. Martínez Estrada había descrito el avance hacia la nada en la inmensidad de la pampa donde el hombre se pierde en su búsqueda como una búsqueda que se convierte en tragedia y en trauma que afectarían incluso la vida contemporánea argentina. Al contrario del autor argentino, pero basándose en el mismo imaginario, Braudel desplaza la mirada desde la perspectiva psicológica-existencial hacia el conocimiento tecnológico cuando equipara la inmensidad del continente con la vastedad del Océano: "Ignorezvous, par exemple," pregunta a sus estudiantes en una de sus cursos, "que [...] les conquérants se dirigeaient à la boussole absolument comme si sur terre on naviguait en haute mer?" (Braudel, L'Amérique 11, el destacado es mío).

Es posible que Braudel solo haya llegado a conocer el ensayo de Martínez Estrada durante su viaje al Brasil, Argentina y Chile en 1947. Fue el caso en cuanto a la obra Chile o una loca geografía, de Benjamín Subercaseaux, ensayista, escritor, psicólogo y antropólogo cuya obra fue publicada en 1940 y que fue reseñada por Braudel para el mencionado número especial de los Annales sobre América Latina en 1948. La mirada insistente del autor chileno sobre la geografía excéntrica de su país, cuya extensión lleva desde el Cabo Norte hasta Sicilia, con sus montañas levantándose desde el nivel del mar hasta 
los 6000 metros de altura, con sus paisajes de desierto, glaciares y huertos fructíferos que influyeron mucho en las poblaciones, como dice Subercaseaux, deben haber llamado poderosamente la curiosidad de Braudel siempre fascinado por la geografía ${ }^{16}$. "Mais en quoi cette géographie, est-elle folle?" se pregunta el historiador para continuar con una respuesta casi solemne: "En ceci, si je ne me trompe [...] que la géographie chilienne résume en elle mille souffrances, mille erreurs de la terre. Et chaque souffrance oblige l'homme à réagir et à s'adapter" (Braudel, Chili 444 ss.). Pero pese al entusiasmo sobre los "plaisirs subtils et savoureux de la folle Géographie", Braudel sostiene que la obra de Subercaseaux, después de todo, queda atrapada en la geografía aunque sí aparecen los seres humanos, habitantes de aquellos paisajes extremos: "Rien de la matière vivante du Chili n'échappe à ce poète qui, pour mieux voir et classer ses thèmes, s'est fait géographe" (ibíd.). Pero el poeta-geógrafo, de hecho, no lograría escribir una "historia completa" de los hombres y de la vida humana en Chile. Aquí, Braudel vuelve a la imagen ya familiar usada por Gilberto Freyre que tiene su origen en la arquitectura tradicional, es decir, la casa multiparte, metáfora de la sociedad entera y compleja y su historia. En este sentido, el libro de Subercaseaux solo presentaría el fundamento del edificio, "un rez-de-chaussée, une fondation", de cierto modo igual a la geografía que solo es el fundamento de la vida humana, pero "elle n'est pas toute la vie des hommes" (ibíd. 446).

Una mirada escudriñadora a las páginas de La Méditerranée et le Monde méditerranéen à l'époque de Philippe II publicado un año después de la reseña al libro de Subercaseaux aclara el papel complejo que ocupa la geografía en la obra de Braudel. En la edición original de 1949, al final de la primera parte se encuentra un capítulo que resume el problema del determinismo geográfico ("Géohistoire et déterminisme", en Braudel, La Méditerranée 295-304). Parece obvio que en aquel período Braudel estaba buscando una solución específica para esta cuestión central a sus preocupaciones; es interesante que en ediciones posteriores, este capítulo ya no se incluye. En

16 La extrema geografía de Chile es, para Subercaseaux, la verdadera base, muy vieja y característica de la nación y sus ciudadanos, un tipo de "geografía nacional": “[...] Chile, cualquiera que sea la raza que lo habite y los trastornos que sufra, quedará en definitiva ocupado por chilenos; por hombres sujetos a una misma historia y a un mismo paisaje que les modelará un mismo carácter, los exaltará en las mismas glorias y los hará sobrellevar las mismas miserias. No olvidemos tan pronto esa facilidad del extranjero para 'chilenizarse' y la parte que le cabe a la tierra en el misterioso proceso" (Subercaseaux 29). 
este texto, Braudel con énfasis toma distancia de las ideas deterministas de la Anthropogeographie en el sentido de Friedrich Ratzel, pero insiste en la iluminación mutua de la historiografía y la geografía. Sostiene, a pesar de su predilección personal por la geografía (y por la fuerza estética que surge a partir de las descripciones geográficas y de los paisajes) que la geografía no puede explicar enteramente ni la vida ni la historia humanas:

Non, la géographie n'explique pas toute la vie, ni toute l'histoire des hommes. La scène sur laquelle ils vivent, si importante qu'elle soit (elle demeure et ils passent) ne commande pas tout. En dehors de sa prise ne cesse de grandir le travail de l'homme sur les choses et de l'homme sur l'homme" (Braudel, La Méditerranée 301).

Para el historiador francés, son, al fin y al cabo, las reacciones de los hombres frente a las "resistencias del ambiente" el verdadero punto de referencia para medir la posible determinación por la geografía. Así, las representaciones sugerentes de la "geografía loca" de Benjamín Subercaseaux habían sido admiradas y aplaudidas por Braudel, pero no le llegaron a parecer suficientes. Al fundamento le faltaría el edificio:

Le Chili ne mérite-t-il pas un portrait plus complet, je veux dire une maison entière? Je comprends le désir de Subercaseaux d'aller à ce qui ne bouge pas, à cette "éternité de l'histoire appuyée sur la géographie", pour lui reprendre une de ses belles formules. Mais la vie s'échappe sans fin de cette immobilité de terre et de pierre" (Braudel, Chili 446).

En resumen, se puede destacar que la "historia à la brasileña", en particular la obra de Gilberto Freyre y su estilo específico, híbrido y ensayístico, fue una fuente impactante e inspiradora para Braudel quien, en aquel momento, estaba en vías de redactar su obra más conocida sobre el Mediterráneo durante los años de su cautiverio alemán en la Segunda Guerra Mundial y en los años de la posguerra. Braudel era un lector apasionado de la obra de Freyre y de otros textos de ensayistas latinoamericanos. Los leía, ante todo, como discursos de búsqueda identitaria. Esta manera de interpretar los textos no es sorprendente en sí, por supuesto; sin embargo, hay que tener en cuenta el momento específico del proceso germinativo de su obra fundacional sobre el Mediterráneo. Esta obra se puede leer como una reflexión y reconstrucción de los fundamentos (geoculturales) del Viejo Mundo, es decir, los fundamentos identitarios, en un momento de profunda crisis debido a la Guerra Mundial. La 
recepción creativa de Freyre y otros ensayistas latinoamericanos demuestra los entrelazamientos sutiles de ideas que surgieron en un mundo en transformación donde se van cuestionando poco a poco las dicotomías entre los centros y las "márgenes" de la historia.

\section{BIBLIOGRAFÍA}

Barthes, Roland. "Maîtres et Esclaves par Gilberto Freyre". Les Lettres Nouvelles 7 (1953): 107-108.

Bataillon, Marcel. Sur l'essence de l'Argentine". Annales, Économie, Sociétés, Civilisations 4 (1948): 439-441.

Braudel, Fernand. L'Amérique latine. [Ciclo de conferencias, tiposcrito] Paris: Institut des Sciences Politiques, 1947/48.

A travers un continent d'histoire. Le Brésil et l'œuvre de Gilberto Freyre". Mélanges d'histoire sociale 4 (1943): 3-20.

"Chili, cette folie géographique". Annales. Économies, Sociétés, Civilisations 4 (1948): 443-446.

Écrits sur l'histoire [1969]. Paris: Flammarion.

"L'histoire, mesure du monde". Les écrits de Fernand Braudel. Vol. 2: Les ambitions de l'histoire. Édition établie et présentée par Roselyne de Ayala et Paule Braudel. Paris: Éditions de Fallois (1997): 11-83.

"Jeu des Portraits. La règle du jeu". Annales. Économies, Sociétés, Civilisations 4 (1948): 437-438.

La Méditerranée et le Monde méditerranéen à l'époque de Philippe II. 2 vols. Paris: Armand Colin ( $2^{\mathrm{a}}$ ed. revisada y ampliada), 1966.

"Personal Testimony". Journal of Modern History 44/4 (1972): 448-467.

Braudel, Paule. "Les origines intellectuelles de Fernand Braudel: Un témoignage". Annales. Économies, Sociétés, Civilisations 1 (1992): 237-244.

Burke, Peter. The French Historical Revolution. The Annales School, 1929-89. Cambridge: Polity Press, 1990.

"Elective affinities: Gilberto Freyre and the nouvelle histoire". The European Legacy: Towards New Paradigms 3:4 (1998): 1-10. DOI: 10.1080/10848779808579896.

Burke, Peter y María Lúcia Pallares-Burke. Gilberto Freyre: Social Theory in the Tropics. Oxford: Peter Lang, 2008.

Fonseca, Edson Nery. Casa Grande \& Senzala e a crítica brasileira de 1933 a 1944. Ed. Recife: Companhia Editora de Pernambuco, 1985.

Freyre, Gilberto. "A propósito de Michelet". Revista Acadêmica 67 ("França") (1946): 17.

Casa Grande \& Senzala. Formação da familia brasileira sob o regimen de economia patriarcal [1933]. 2a ed., Rio de Janeiro: Schmidt, 1936. 
Casa Grande y Senzala. Formación de la familia brasileña bajo el régimen de la economía patriarcal. Prólogo y cronología de Darcy Ribeiro. Caracas: Biblioteca Ayacucho, 1977.

"História além dos textos". En Gilberto Freyre. 6 conferências em busca de um leitor. Rio de Janeiro: José Olympio, 1965. 114-149.

Maîtres et Esclaves. Trad. Roger Bastide, prólogo de Lucien Febvre. Paris: Gallimard, 1952.

Guia prático, histórico e sentimental da Cidade do Recife [1934]. 4ª ed. revisada e ampliada. Rio de Janeiro: José Olympio.

Gemelli, Giuliana. Fernand Braudel. Paris: Odile Jacob, 1995.

Gerstenberger, Debora. “Gilberto Freyre, um teórico da globalização?” História, Ciências, Saúde-Manguinhos 21/1, 2014. http://dx.doi.org/10.1590/S0104-59702013005000015

Hexter, Jack. "Fernand Braudel and the Monde Braudelien...". Journal of Modern History 44/4 (1972): 480-539.

Leenhardt, Jacques. "A consagração na França de um pensamento heterodoxo". Reinventar $o$ Brasil. Gilberto Freyre entre história e ficção. Eds. Antonio Dimas; Jacques Leenhardt; Sandra Jahanty Pesavento. Porto Alegre: UFRGS/USP. 2006. 25-40.

Martínez Estrada, Ezequiel. Radiografía de la Pampa [1933]. Ed. crítica, Leo Pollmann ed., Paris: Colección Archivos.

Mauro, Frédéric. "L'apport du Brésil aux études en Sciences Sociales et Humaines". Images réciproques du Brésil et de la France/Imagens recíprocas do Brasil e da França. Vol. 2. Eds. Solange Parvaux y Jean Revel-Mouroz. Paris: IHEAL (Collection Travaux et Mémoires de l'IHEAL 46) 1991. 735-736.

Schöttler, Peter. "Fernand Braudel, prisonnier en Allemagne : face à la longue durée et au temps présent”. Sozial.Geschichte Online 10 (2013): 7-25. URL: http://duepublico.uniduisburg-essen.de/servlets/DocumentServlet?id=30963

Subercaseaux, Benjamín. Chile o una loca geografía. 1940. Prólogo de Gabriela Mistral. Santiago de Chile: Ercilla, 1956.

Weinberg, Liliana. Pensar el ensayo. México: Siglo XXI, 2007. 